\title{
AS BELAS MORTES DE SÓCRATES E O ENCANTAMENTO DA CELEBRAÇÃO DOS MORTOS EM ATENAS ${ }^{1}$
}

\author{
Adriano Machado Ribeiro
}

\begin{abstract}
RESUMO
O propósito deste artigo é mostrar que em Platão há um elogio de Sócrates em vista do modo pelo qual ele morreu e compreendeu a morte. Tanto no Fédon quanto na Apologia, Platão visa a tornar claro que o filósofo atinge a morte em consequência da melhor escolha de vida. No Menexeno, ao contrário, o elogio fúnebre torna, pelo encanto das palavras que se pronunciam publicamente, a vida dos cidadãos mais importante do que ela realmente era.
\end{abstract}

PALAVRAS-CHAVE: Platão. Morte de Sócrates. Imortalidade da alma. Elogio fúnebre.

$1 \mathrm{O}$ texto a seguir, com várias modificações, foi primeiramente apresentado na Universidade Federal de Uberlândia por ocasião do lançamento do livro do prof. Rubens Nunes Sobrinho que é citado na referência. Para as passagens em grego, optou-se por transliterá-las sem a diferenciação entre vogais longas e breves, dados os problemas de acentuação que disso decorreriam e em virtude de todas elas serem referentes a textos de Platão e Aristóteles claramente assinalados. Quanto a estes, foram eles citados e traduzidos a partir dos textos estabelecidos nas edições citadas na referência, seguindo a paginação canônica. Para melhor fluência na leitura, foram eles mencionados abreviadamente, ou seja, Ap. para Apologia de Sócrates; Féd. para o Fédon; Menex. para o Menexeno e Ep. VII para as Epístolas de Platão. A Arte Retórica de Aristóteles aparece citada como Ret., seguindo a versão da Oxford estabelecida por W. D. Ross.

* Doutor em Filosofia pela Universidade de São Paulo e Professor da Universidade de São Paulo. E-mail: adrianor@usp.br 


\section{RÉSUMÈ}

Le propos de cet article est montrer que il ya chez Platon l'éloge de Socrate en vue de la compréhension et de la façon par laquelle il est mort. Que ce soit dans le Phédon ou dans l'Apologie, Platon vise à éclairer que le philosophe arrive à la mort comme consequence du meilleur choix de vie. Dans le Ménexène, au contraire, l'éloge funèbre fait devenir, par l'enchantement des mots qu'on prononce publiquement, la vie des citoyens plus importante qu'elle réellement était.

MOTS-CLÉS: Platon. La mort de Socrate. Immortalité de l'âme. Eloge funèbre.

O tema da bela morte apresenta-se para os helenos, como bem o mostra Vernant (1979, p. 31-62), já de modo claro em Homero. O impasse da escolha de Aquiles - ou morrer jovem e gloriosamente ou velho e para sempre esquecido - traz implicações que, por assimilação ou rejeição, estarão de algum modo presente nos textos posteriores da Hélade. ${ }^{2}$ Certamente um tópos, nem por isso as configurações do uso deste lugar deixarão de talhá-lo em conformidades argumentativas com implicações políticas, filosóficas e históricas, sem que se possa com clareza deslindar uma de outra parte desta relação.

Sendo assim, também em Platão a questão da morte se propõe diversamente, com nuanças que se modelam diferentemente em seus diálogos, chegando por vez, inclusive, Platão a aproximar o Sócrates da Apologia à escolha dilemática de Aquiles, sem que por isso não se deixe de instalar enorme distância entre um e outro. Para além de uma ocorrência, o uso pode ser paródico, conformando um discurso, como o Menexeno, com toda a topologia do discurso epidítico fúnebre, deixando ao leitor perscrutar a razão de tal uso, a fim de verificar, inclusive, se uma ou outra parte não se diz em consonância com o pensamento do que Platão pensava sobre a morte. $\mathrm{Ou}$

\footnotetext{
${ }^{2}$ Aristóteles, ao afirmar que no gênero epidítico, por elogiar ou censurar, a finalidade principal é mostrar que alguém fez ou não uma bela ação, destacando-se o belo em detrimento do que é ou não útil, exemplifica do seguinte modo: "por exemplo, louvarse-á Aquiles por ter socorrido Pátroclo, seu amigo, sabendo ele que morreria quando poderia viver. Era para ele mais belo morrer assim. Mas seu interesse era o de conservar a vida" (Ret. 1359a).
} 
mesmo, em refino do modelo, reinventando a bela morte, filosoficamente, tal como nos mostra as iluminadas e sombrias páginas do Fédon.

O objetivo deste artigo será, pois, o de apresentar três momentos diversos da configuração da morte nos textos de Platão. Dois deles apresentam a perspectiva socrática da morte. No Fédon, dramaticamente, narra-se a própria morte de Sócrates, destacando o êthos da personagem nos momentos finais de sua vida para destacar a argumentação do diálogo, no qual se apresentam teses que justificariam a imortalidade da alma. $\mathrm{Na}$ Apologia, por sua vez, a morte, sem a implicação de uma alma imortal, é contraposta à valorização de uma vida cujo escopo central é filosofar, único modo em que o viver se justificaria para Sócrates. Se a morte nada for, tal vida por si só se justifica. Se ela for algo, seu valor dar-se-á como prolongamento desse único viver que vale a pena, ou seja, lá como cá deve-se filosofar. Por fim, terceiro momento a ser aqui analisado, Platão não apresenta a personagem de Sócrates como nos dois textos anteriores; com efeito, no Menexeno não se dramatiza a morte de Sócrates, como no Fédon, nem se apresenta como uma perspectiva sua sobre a morte, como se faz na Apologia. Ao contrário, discute-se como a cidade de Atenas celebra os mortos que por ela morreram em batalha, a partir, portanto, dos valores cívicos e políticos da pólis, sem que se avaliem e se justifiquem tais valores, ou seja, sem que se discuta filosoficamente este modelo encantatório pelo qual um orador louva, ao homenagear os mortos, a excelência do que para Platão deveria ser discutido: o fim da vida como encontrando sua finalidade na virtude cívica do cidadão de Atenas.

\section{I}

O Fédon se inicia com a pergunta de Equécrates sobre a presença ou não da personagem que dá o nome ao diálogo nos momentos que antecederam a morte de Sócrates. Como a resposta daquele é afirmativa, esse pede uma diégesis que relate o fato, explicitando o foco de seu interesse: "que coisas disse o homem antes da morte ("prò toû thanátou")? Como chegou ao fim ("eteleúta")?" (Féd.57a). Equécrates explica, ademais, a razão da questão: há muito nenhum dos cidadãos de Fliunte costuma 
visitar Atenas; há bastante tempo nenhum estrangeiro chega de lá capaz de relatar precisamente como Sócrates morreu depois de tomar o veneno.

É importante lembrar que, finda a Guerra do Peloponeso, a Atenas da morte de Sócrates parece ter se isolado das demais póleis. A antiga força, celebrada nas páginas de Heródoto e representada na obra de Ésquilo, da cidade que enfrentou em Maratona os Persas e daí novamente se fortaleceu para combatê-los com os espartanos em Salamina e Plateia parece distante de sua plenitude. A voz silenciada de Sócrates parece ecoar nesta ausência, na configuração de Platão, dando à morte seu verdadeiro sentido: a presença socrática funcionaria assim como espaço de refundação da cidade a partir da reproposição de uma Atenas que se estende à Hélade não mais por seu imperialismo e força militar, mas pela reinstauração de propósitos a partir da presença socrática e dos estrangeiros que estavam presentes em sua cena derradeira, como se ali Atenas se reencontrasse por uma philía.

Sabe-se apenas à distância, diz Equécrates, que entre o julgamento e a morte um largo tempo transcorreu, sem se poder dar a razão do porquê disso. Fédon então traz a notícia: no dia anterior ao início do processo, foi coroado o navio que Atenas envia anualmente a Delos, promessa dos atenienses a Apolo cuja razão encontra-se na volta de Teseu de Creta. No início desta peregrinação é nómos neste período "manter purificada a cidade e não haver nenhuma execução pública" ("kathareúein tèn pólin kaì demosíai medéna apokteinúnai") (Féd.58b). Tal ritual se inicia com a coroação, por parte do sacerdote de Apolo, da proa do navio. O julgamento e morte de Sócrates assim se dão sob a condição purificadora da kátharsis. ${ }^{3}$ Como Teseu é o herói fundador da cidade, há a implicação, pelo início do relato que o evoca, do fim de um ciclo, de uma morte de Atenas concomitante à morte de Sócrates. O navio que levou Teseu e libertou Atenas agora mata Sócrates. Por isso, é preciso uma segunda navegação, uma refundação de Atenas que a liberte de seus equívocos que ora culminam no maior de todos: matar, em nome de um valor moral, o mais valoroso dos homens (Ep.VII,325c). As páginas que se seguirão do Fédon irão assim lançarse a este desafio náutico, que, enfim, não separa o itinerário filosófico de

\footnotetext{
${ }^{3}$ Ver para tanto as análises presentes ao longo do livro de Nunes Sobrinho (2007).
} 
Sócrates de uma perspectiva política.

Équecrates, no entanto, volta à questão, querendo saber "as coisas relativas à morte" de Sócrates ("tà perì autòn tòn thánaton"). O relato da demora na execução então se explicita. É preciso saber os motivos pelos quais houve a demora, porque se trata de explicitar "as coisas ditas e realizadas" ("tà lechthénta kaì prachthénta") (Féd.58c) anteriormente ao final do diálogo cujo relato coincide com o fim da vida de Sócrates, como se, retomando a República, a morte do herói cuja conduta é irretocável fosse, pela narrativa que distancia o modelo de sua imitação, a possibilidade de dramatização modelar por narrar em vida o enfrentamento altivo da morte. ${ }^{4}$

A pólis, correspondentemente, distante em ausência, não se apresenta a não ser por seu matiz religioso e um equívoco condenatório; com efeito, responde Fédon, Sócrates não morreu só, mas acompanhado de muitos amigos. Nesta refundação que deve reinventar a pólis, a philia absorve o espaço antes reservado aos cidadãos: os laços ora se fazem em presença da morte a partir de uma comunidade que - ainda que agregue membros da família e um ou outro admirador descompassado - revela sobretudo a junção de um termo comum, a morte altivamente descrita, e sua presença na vida de todos, visto por ela se reforcem tais laços e se modifique o próprio sentido que ela possa ter.

É essa perspectiva que se apresenta desde o início da fala de Fédon, quando ele inicia propriamente a diégesis, apresentada por esta mímesis inicial. A narração de Fédon insiste na discrepância entre o que comumente implicaria o páthos esperado para a morte e a contraposição do comportamento de Sócrates, que quebra tal expectativa. Sendo assim, diz Fédon, foi isso o mais surpreendente, pois ele próprio "não sentiu piedade alguma, mesmo estando presente à morte de um amigo, pois esse se mostrava feliz" ("hôs thanátoi parónta me andròs epitedeíou héleos eiseiêei· eudaímôn gár moi anêr ephaíneto") (Féd.58e). Embora os amigos, mesmo sem o páthos da lamúria e do lamento (pénthos), comuns a tais

\footnotetext{
${ }^{4}$ Em Fédon 58d, ao pedido de Equécrates que tudo recite (prothuméthêti), caso não esteja ocupado (ascholia), Fédon afirma que narrará, dado o fato de lhe "ser sempre agradável lembrar Sócrates, seja ao falar eu próprio dele ou ouvindo alguém que dele fale" ("memnêsthai Sôkrátous kaì autòn légonta kaì állou akúonta émoige aeì pántôn hédiston") (Féd.58d)
} 
ocasiões, não se rendem completamente ao prazer (hedoné) normalmente associado para Fédon à presença deles na philosophía. É por este misto de prazer e dor (lýpes), a partir do qual Sócrates também inicia o diálogo ao ser desamarrado, que se apresentam as personagens com ele dialogando em seu momento final. Há uma mescla de riso e choro na cena. Mas este só é particularmente notável e visível em Apolodoro. É ele quem chora excessivamente, visto seja o único ali estranho ao éthos da filosofia.

Por isso importa realçá-lo para contrapor seu comportamento ao dos demais. Sobretudo para sobrelevar o de Sócrates. A discussão, o lógos, que se seguirá, tematizará a morte que no fim do diálogo se incorporá na cena final, sem ação dramática, mas como coroamento da vida de Sócrates: liberta do corpo, a alma imortal, sem suicído e precipitação, justifica a vida que a ela acalanta e por ela se organiza. A morte corpórea de Sócrates no Fédon é tornar pleno o exercício pelo qual a vida inteira sua ação modelou-o, ou seja, a atividade da própria alma. A Filosofia é aqui vista como disciplina que lança hipóteses a serem discutidas entre pares, modelando um êthos de uma phília que responde às exigências de uma vida imortal que deve, necessariamente, como Platão mostra na República, reorganizar a pólis e a vida dos demais mortais que nela habitam. Sócrates exemplarmente a ela se dirige e dramaticamente explicita a bela morte pela filosofia, termo final e fundamental do distanciamento do corpo para a plenitude da alma imortal que se explicita como modelo para o éthos dos que ainda vivem.

\section{II}

A preparação para a morte que o Fédon apresenta mostra-se de maneira distinta na Apologia. Nessa a sentença de morte proclamada pelos atenienses, como ali diz o Sócrates de Platão, num terceiro discurso que teria sido apresentado no tribunal após a proclamação da condenação (Ap.38c), por pouco lança Atenas, pela decisão de seus homens, no risco de ser vilipendiada ("loidorein"); com efeito, se eles aguardassem um pouco mais, o próprio tempo incumbir-se-ia de fazê-lo: a idade de Sócrates, segundo o que este ali afirma, levá-lo-ia em breve a cumprir o que a 
sentença objetiva, sua morte, e os atenienses por ela não precisariam ser responsabilizados. Sócrates afirma assim dela não fugir, nem por carência de lógoi (já que estes, conforme traça a Apologia desde o início, devem se organizar segundo sua atividade, o seu érgon); nem por comportamento indevido (a mesma ausência de apelo ao páthos aqui e ali se deixam ver). Afinal, diz ele: importa mais após assim ter se defendido morrer do que viver apresentando-se diversamente no tribunal do modo pelo qual sempre conduziu sua vida, com um érgon diferente para que melhor se moldasse às circunstâncias com o fito de querer ser absolvido pelos que lá o julgaram.

A morte é aqui, pois, proposta como consequência secundária de outra, prioritária, o modo de vida e ação. Sendo assim, morrer injustamente, tendo a justiça do seu lado, é passo determinante e mais importante do que os que seguem vivendo condenados pela verdade em injustiça (Ap.38b). $\mathrm{E}$ assim, próximo à morte, Sócrates oraculariza aos que o condenaram: punidos serão seus atuais punidores, já que, passo fundamental, a ausência de Sócrates em Atenas os tornará para sempre indiferentes ao que para ele é fundamental na vida, "o justificar sua vida submetendo-se à refutação" ("tou didónai élenchon tou bíou") (Ap.38c).

Mas essa profecia de Sócrates, lançando a ação presente da escrita de Platão como socraticamente futura, já que posterior a sua enunciação, prevê muitos outros Sócrates nele se espelhando e espalhando-se pela cidade. $\mathrm{O}$ próprio Platão assim o reverbera em seu texto. $\mathrm{O}$ equívoco, segundo ele, está no passo primeiro, erro inicial: não se escapa a este exame pela eliminação de um interrogador, mas sim, preparando-se a si mesmo da melhor maneira para se tornar o melhor possível (Ap.39d).

Por outro lado, aos que o absolveram, Sócrates agradavelmente propõe-se a com eles dialogar. Aos juízes que, segundo ele, justamente são assim designados, Sócrates aponta os passos firmes pelos quais nada equivocado ocorreu. Em primeiro lugar, seu daimon não se manifestou contrário às atitudes que ele ali tomou, justificando a retitude de sua ação (Ap.40b); em segundo, deve-se analisar qual o sentido que pode ter a morte para saber se ela é um mal ou um bem (Ap.40b-c).

Duas possibilidades são assim apresentadas: na primeira a morte nada mais é do que um nada ser, permanente ausência em que nada se sente. Se tal, ela seria como uma noite de sono sem sonhos. Momento mais 
agradável quando comparado a qualquer noite de sonhos, a morte aqui seria um enorme ganho (Ap.40c-d).

Mas, segunda possibilidade, se for a morte a ida para outra região, Sócrates igualmente a vê como bem maior, pois o que morre encontrar-se-ia com aqueles grandes homens e deuses. E, nesse ponto, importa deter-se nas palavras de Sócrates; com efeito, lá ele encontrará justos juízes e homens igualmente injustamente condenados, como, por exemplo, Palamedes, que, curiosamente, recebera uma defesa retroativa de Górgias. Lá o maior prazer será então refazer o que em vida ele cá já fazia: "examinar e investigar" ("exetázonta kaì ereunônta") os que ali estão (Ap.41b): Agamênon, Odisseu e milhares de outros, homens e mulheres. ${ }^{5}$ O dialogar e com eles associar-se para investigar configura para o Sócrates que Platão aqui apresenta ser uma imensurável felicidade, ou seja, "com eles dialogar, associar-se e examiná-los" ("hoîs ekeî dialégesthai, kaì xuneînai kaì exetázein améchanon án eîê eudaimonías") (Ap.41c).

No mais, um toque de sutil ironia: lá assim viver não implicará o risco de morrer por viver assim, pois a imortalidade seria de antemão garantida. A vida é plena eudaimonía, sem riscos e ameaças. Desse modo, por configurar a permanente atividade do questionamento como meta suprema e permanente atividade - sobretudo da pólis de Atenas e suas inumeráveis atividades - a vida assim se apresenta sem desvios e a morte é resposta por implicar um permanente e eterno interrogar.

Morrer implica, pois, consequência do que anteriormente fora exposto, um único e verdadeiro pensar: "ao homem bom (agathô andrí) não há nenhum mal (kakòn oudèn)" (Ap.41c-d), nem vivo nem morto, pois nem os deuses negligenciam os fatos que a ele concernem. Assim, Sócrates conclui que, nada tendo acontecido por acaso, o melhor que lhe poderia ocorrer agora efetivamente se dá, ou seja, ele se livra de suas tarefas (pragmátôn) justamente porque teria cumprida sua atividade numa cidade em que ora seus concidadãos o condenam. Não há, diz ele, raiva contra seus acusadores, mas apenas a censura por eles crerem que com a condenação podem chegar a prejudicá-lo. Ao contrário, as palavras finais

\footnotetext{
${ }^{5}$ Característica inequívoca deste exame: quem pode fazê-lo só por ele justifica duplamente, em ação e palavra (érgon e lógos) sua própria vida.
} 
de Sócrates para os homens que o absolveram é que estes cuidem dos filhos dele tal qual esse apresentou-se em vida em Atenas: sua morte deve ser modelar para efetivar os érga de seus antepassados modelados nas ações e palavras do pai enquanto esse viveu: como Sócrates, eles não devem se preocupar nem com dinheiro "nem com qualquer outra coisa que não seja a virtude" ("epimeleisthai é aretês") (Ap.41e).

$\mathrm{O}$ indagar e o examinar refutativo configuram o érgon socrático na Apologia como o permanente uso de lógoi que se justificam ao permanentemente investigar os valores pelos quais os homens justificam seu modo de vida. Esses serão sempre voltados para as questões mais prementes ao homem e, em última instância, as que efetivamente lhes concerne: os valores morais. Distante do sóphos que almeja alcançar um saber divino, o Sócrates que Platão configura na Apologia cumpre a determinação do deus no que ela especifica como humano: a impossibilidade de abarcar a compreensão da phýsis especifica um território de incertezas no qual o homem pode atingir a verdade: o philosopheîn (o filosofar) é érgon (atividade), cuja ação só se dá no permanente apresentar razões (didónai lógon), num permanente ato de justificar-se a si mesmo e às atividades praticadas por cada um.

Por isso, viver é muito perigoso, já que este apresentar razões de sua ações lança-se não solitariamente, mas só se efetiva na fala com outro, visto implique o dialogar (dialegesthai). Só assim a vida vale a pena: morrer ou será permanente ausência, implicando a descaracterização da perturbação com os valores humanos e, como consequência, a impossibilidade de investigar e examinar um ao outro; ou será, sem risco, a plenitude de indagar e questionar os homens que de algum modo ou de outro disseram lógoi que os demais homens julgaram servir como referência de ação. Nisso tudo, o saber se propõe como meta, pois mesmo com sua asserção de ignorância o Sócrates que aqui Platão apresenta nunca negou a prioridade da distinção do reconhecimento da oposição entre o bem e o mal como modelador de um viver que se configura como paradeigma exemplar para a própria morte. 


\section{III}

Da morte tal como apresentada no Fédon para aquela presente na Apologia, há mais do que a distância de um mês, como dramaticamente Platão afirma no início daquele diálogo. Mas não há, no entanto, uma rota de colisão: à vida como atividade que se valora devidamente apenas e tão somente pelo filosofar, e que se apresenta a todo aquele que queira pelo dialogar prestar conta e razão de si para outro (Ap.29e), substitui-se uma outra, no Fédon; vida essa que encontra sua plenitude no exercício de uma disciplina determinada, pois implica um éthos para melhor conformar uma alma imortal. Para tanto, cabe à dialética, disciplinarmente empregada a partir de referências a um cultivo estabelecido na proximidade de amigos que ao mesmo éthos se conformam. Mas de uma a outra permanece a verdade como meta a se alcançar e pela qual se deve conformar a própria atividade; sobretudo, perdura a presença do bem como ponto norteador e condutor de qualquer vida ou morte que valham a pena de serem enfrentadas e justificadas.

Outra, contudo, é perspectiva da morte pública em Atenas: a morte pela pólis de soldados que, ao mesmo tempo, são os cidadãos que em batalha morrem em defesa da cidade e de seus valores. O Menexeno de Platão dá uma imagem dessa morte pela pólis por meio das lentes de quem com ela não concorda.

Primeiro passo a salientar, tal morte não se afirma como tal. $\mathrm{O}$ verbo teléô, usado, sobretudo no perfeito, insiste que os homens ali presentes em cerimônia pública cumpriram seu fim, realizaram o que deles se esperava, levando a termo sua obra. Ele substitui o emprego do morrer, estar morto. Não se trata, pois, de morrer pura e simplesmente pela cidade, mas de cumprir e finalizar uma tarefa em nome dela, como salienta N. Loraux (1993, p. 3).

O texto, como o da Apologia, curiosamente é um dos poucos em que Platão apresenta um longo discurso. Diversamente desse, contudo, o Menexeno abre e se encerra na molda do dialogar, com Sócrates conversando com o interlocutor que intitula a obra. Dramaticamente, sem a diégesis do Fédon, o Menexeno lança-se ao leitor na indeterminação em que o interlocutor se apresenta pela ação da personagem no próprio diálogo. Dá-se assim, pois, margem a uma imprecisão de contornos explícitos para que a personagem 
funcione como a especificação tipológica de uma variável. Nesse caso, um jovem que, desde o início, apresenta ambições políticas apropriadamente sugeridas como uma tradição familiar. Assim se inicia o diálogo:

S.: Vem Menexeno da ágora ou de outro lugar?

M.: Da ágora, Sócrates. De fato, da sede do Conselho.

S.: Que interesse particular você tem na sede do Conselho? Evidentemente, você sem dúvida pensa estar na etapa final da educação e da filosofia, e porque, a seu ver, já as tem satisfatoriamente, crê voltar-se para as questões mais importantes, e, homem admirável, embora tão jovem, você tenta governar-nos, homens mais velhos, para que sua casa nunca deixe de fornecer alguém que cuide de nós?"(Menex.234a-b)

O contraponto é claro: ao velho Sócrates da Apologia e do Fédon, para quem a filosofia é uma conquista que se alcança por longo percurso, como toda a República deixa claro, apresenta-se aqui um jovem que já a crê possuir, talvez porque a modele de acordo com o exemplo isocrático. Sendo assim, ele já poderia inclusive governar os demais cidadãos.

Menexeno, contudo, não vai tão longe, pois explicita que isso só fará se receber o aval socrático: "Se, de fato, Sócrates, você me permitir e aconselhar governar, eu estarei pronto a fazê-lo. Mas se não, não" (Menex.234b). Mas é outra e mais imediata a preocupação presente do jovem, a questão para os funerais públicos, pois seu desejo é saber quem será o orador na cerimônia que ocorrerá no dia seguinte.

Sócrates deixa, então, de lado, nomes para ater-se ao que o érgon traz, enquanto celebração pelas palavras, de específico. Mais do que isso, é preciso avaliar o sentido desta morte coletiva, em que diferenças se apagam do viver pela permanência proposta do fim comum:

[...] Menexeno, por diversas razões, seguramente, é possível que seja belo morrer em batalha; com efeito, se morre alguém pobre, este obtém um belo e majestoso funeral; se é um miserável, obtém um elogio, por homens sábios e que elogiam não de improviso, mas com discursos há muito tempo preparados. (Menex.234c) 
Importa, pois, antes de mais nada destacar - o que o início propriamente do discurso ainda mais reforçará (Menex.236d) - não haver, como Sócrates afirma na Apologia, uma correspondência equivalente entre érga e lógoi, ou seja, entre as ações e as palavras há um desnível pelo qual essas engrandecem aquelas. Mais do que isso, a palavra edifica um sentido da vida que, encantatório, dignifica os vivos independentemente do seu viver singularmente avaliado. Longe de investigar as razões da vida e dela dar razões; ou disciplinarmente modelar-se por um éthos que se conforma ao rigor da melhor hipótese, que implica o incessante remodelar-se da alma, o encantamento lança o cidadão a crer-se maior do que efetivamente é, num prolongamento que só tem sentido porque se ancora numa realização coletiva:

Estes elogiam tão belamente que enfeitiçam nossas almas, não só falando as coisas que são e não presentes acerca de cada um, de certo modo bordando em cores as coisas mais belas, mas também louvando de todas as maneiras os mortos na batalha e todos nossos ancestrais, e elogiando a nós mesmos que ainda vivemos; tão belamente que eu próprio me comporto muito mais nobremente ao ser elogiado por eles, e a cada ocasião tenho me exaltado ao ouvi-los e ficar encantado, crendo neste momento ter me tornado maior, mais nobre e belo. (Menex.235a-b)

Tal sentimento reforça-se com o lógos que atinge o ouvinte estrangeiro e, reforçando-lhes a grandiosidade de Atenas, firma uma identidade pela qual o cidadão ateniense se crê superior pelo olhar admirado de quem sendo de fora da cidade, após ter ouvido o discurso, encantara-se com esse. E esta sinestesia encantatória não termina aí: prossegue, diz Sócrates, numa ilusão que dura alguns dias, tal a força da apáte que dele deriva:

[...]E em mim esta respeitabilidade permanece mais de três dias. Assim o lógos é como uma flauta e o som vindo de quem fala adentra aos ouvidos de modo que apenas no quarto ou quinto dia lembro-me de mim mesmo e percebo que sou da terra, já que até então pensava habitar na ilha dos bem-aventurados, tão hábeis são nossos retores! (Menex.235b-c) 
Há, aqui, pois a possibilidade de Platão atacar a retórica no campo que a ela é própria. Essa, com efeito, no Górgias é criticada a partir de uma perspectiva que lhe rejeita a pretensão de uma téchne, pois neste diálogo é central afirmar-lhe a sua ausência de conhecimento específico. O Menexeno, por sua vez, parece lançá-la à crítica por rapidamente apontar, no curto diálogo que precede o discurso, o que este efetivamente efetua ao ser recitado, como, inclusive, Sócrates mostrará mais à frente. É como se o Menexeno particularizasse e efetuasse na prática os pressupostos do Górgias. ${ }^{6}$ Assim, ao ser indagado por Menexeno se tal expediente retórico é previamente preparado, sendo modelado a partir do uso de tópoi, Sócrates refere a facilidade de agradar da fala epidítica aqueles que a ouvem, diversamente da retórica da antirretórica (ROSSETTI, 1998, p. 109-111) presente na Apologia:

Cada um deles tem discursos preparados sobre isso. E também não é difícil improvisar sobre tais coisas; com efeito, se fosse preciso falar bem dos ateniense entre espartanos, ou dos espartanos entre atenienses, seria preciso de um bom retor capaz de persuadir e obter boa reputação. Mas quando se disputa entre aqueles mesmos que se elogia, não é nada extraordinário parecer falar bem. (Menex.235d)

Mais do que isso, Sócrates, indagado por Menexeno, diz que ele próprio seria capaz de fazê-lo, pois tem como mestre Aspásia, que, segundo ele, ensinou o próprio Péricles a fazer sua famosa oração fúnebre. Por isso, Sócrates diz ser capaz de reproduzir esta argumentação retórica que se faz em repetição, como se o plano do lógos estabelecesse permanentemente um dado encantatório do qual fosse preciso e necessário apenas a reprodução. Não há assim uma investigação que se empreenda para elogiar os cidadãos que chegaram ao termo de suas vidas lutando

6 "Dans le Gorgias, la rhétorique fait objet d'une critique générale, explicite, conduite du point de vue éthico-politique; le Ménexène étaie cette critique sur un cas particulier - l'épitaphios - qui lui permet, sous une forme plus ou moins implicite, d'attaquer la rhétorique et de dénoncer ses effets pernicieux sur la cité en s'appuyant sur des arguments tirés de l'histoire d'Athènes." (Loyaza in PLATON, 2006, p.16). 
pelo bem da cidade. Variável de um tópos, os lógoi pronunciados em tais cerimônias apenas se reapropriam do que permanentemente está a mão em tais eventos. Apagando-se o que efetivamente se realizou ou não na vida, tais lógoi pelo encanto produzido efetua nos afetos uma agradável e segura afirmação da parte - o cidadão - por estar inserido num todo, a pólis. Por isso, Sócrates exemplifica com um discurso que não é seu, mas de Áspasia:

Eu, a partir de mim mesmo, talvez nada [tenho a dizer]. Mas ontem escutei Aspásia recitar um discurso fúnebre sobre estes mesmos homens. De fato, ela ouviu falar o que você dizia, que os atenienses estavam prestes a escolher quem falará. Em razão disso ela discorriame as coisas que seria preciso falar: algumas, de improviso; outras, tendo-as pensado previamente, no tempo em que, me parece, compunha o epitáfio que Péricles apresentou, tendo reunido de improviso alguns pedaços neste momento" (Menex.236b)

A morte coletiva, celebrada pelo lógos epitáphios, efetiva assim uma morte coletivamente engrandecedora. Para tanto, funciona como um encantamento cuja fórmula comum, utilizável em múltiplas variações e ocorrências, implica a celebração do que se não investiga, pois distancia o lógos de um érgon que se justifica e dá razões para uma ou outra atividade efetivamente realizada, como deixa claro a Apologia. Nem é esta morte coletiva comparável com a vida filosófica tal qual Platão propõe no Fédon, pois ali esta resulta de um érgon modelado em função da morte física, visto que neste diálogo o viver filosófico se apresente como exercício constante de uma alma que é imortal, cuja perfectibilidade só se atinge com a separação do corpo, pois o lógos e o érgon do filósofo têm como parâmetro a imortalidade anímica que é alcançada apenas com a morte do corpo. As belas mortes de Sócrates assim o são, porque se configuram como coroamento de uma vida voltada ao melhor de si. E mesmo que Platão possa distintamente compreender o que isto significa, nunca se confundem tais mortes com aquela que se mescla a um consenso geral que não dá razões, posto que opere pelo encanto e engrandeça indistintamente vidas que sem tal glorificação coletiva nada teriam a dizer de si mesmas. 


\section{Referências}

ARISTOTELIS. Ars Rhetorica. Oxford: Oxford University Press, 1975. LORAUX, Nicole. L'Invention d'Athènes. Histoires de l'oraison funèbre dans la "cité classique". Paris: Payot, 1993.

NUNES SOBRINHO; Rubens G. Platão e a imortalidade: mito e argumentação do Fédon. Uberlândia: Edufu, 1987.

PLATO. Timaeus, Critias, Cleitophon, Menexenus, Epistles. Translated by R.G. Bury. London: Willian Heinemann, 1981.

. Republic. Tranlated by Paul Shorey. London: Willian Heinemann, 1987.

. Euthyphro, Apology, Crito, Phaedo, Phaedrus. Translated by H.N. Fowler. London: Willian Heinemann, 1982.

PLATON. Ménexène. Présentation et traduction par Daniel Loayza. Paris: GF Flammarion, 2006.

ROSSETTI, Livio. Rhétorique de l'Anti-Rhétorique et Effet de Surprise: à l'origine de l'image négative des sophistes. Nice, Noesis, n. 2, 1998, p. 105-118.

VERNANT, J-P. A bela morte e o cadáver ultrajado. São Paulo, Discurso, n. 9, 1979, p. 31-62.

Data de registro: $26 / 11 / 08$ Data de aceite: 21/10/09 
